\section{Revista de Literatura, História e Memória}

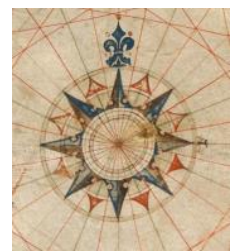

Dossiê: Feminismos e literaturas

ISSN 1983-1498

VOL. 17 - No 30 - 2021

U N I O E S T E / CA S C A V E L - p. 146-158

\title{
A OBRA DE CONCEIÇÃO EVARISTO E O FEMINISMO DESCOLONIAL
}

\author{
The work of Conceição Evaristo and descolonial \\ feminism
}

\author{
Ana Paula Freitas dos Santos ${ }^{1}$
}

RESUMO: Minha pesquisa tem como título: "Os contos de Conceição Evaristo e a representação da mulher negra: diáspora, gênero e descolonização", portanto, procuro no debate póscolonial, os feminismos que deem conta da diáspora das mulheres africanas, da opressão de gênero racializada e da luta dessas mulheres para terem voz, contarem suas narrativas e serem representadas em sua história anticolonial, rejeitando séculos de silenciamento, apagamento, objetificação e estereotipação na Literatura Brasileira. "Rumo a um feminismo descolonial", artigo de María Lugones (2014), é um desses possíveis mapas de rastreamento que nos ajudam a localizar os diversos feminismos de mulheres latino-americanas em suas vivências e "escrevivências" (grifo meu) que Conceição Evaristo narra em seus livros de contos: Olhos d'água (2016) e Insubmissas lágrimas de mulheres (2016), onde a mulher negra é representada em sua complexidade, humanidade e universalidade que reúne as experiências comuns do "ser mulher negra" na América Latina.

PALAVRAS-CHAVE: Feminismo Descolonial; Literatura; Escrevivências; Amefricanidade.

ABSTRACT: My research is entitled: "The tales of Conceição Evaristo and the representation of black women: diaspora, gender and decolonization", therefore, I look for in the postcolonial debate, the feminisms that take into account the diaspora of African women, the oppression of racialized gender and the struggle of these women to have a voice, tell their narratives and be represented in their anti-colonial history, rejecting centuries of silencing, erasure, objectification and stereotyping in Brazilian Literature. "Towards a decolonial feminism", article by María Lugones (2014), is one of those possible tracking maps that help us locate the various feminisms of Latin American women in their experiences and "escrevivências" (my emphasis) that Conceição Evaristo narrates in her short stories: Olhos d'água (2016) and Unsubmissive tears of women (2016), where the black woman is represented in her complexity, humanity and universality that brings together the common experiences of "being a black woman" in Latin America.

KEYWORDS: Decolonial Feminism; Literature; Escrevivências; Amefricanidade.

Minha pesquisa versa sobre os contos de Conceição Evaristo e a representação da mulher negra na Literatura Brasileira, a diáspora africana, gênero e descolonização. Encontro, no debate pós-colonial, os feminismos que dão conta da diáspora das mulheres africanas, da opressão de gênero racializada e da luta dessas mulheres para terem voz, contarem suas

\footnotetext{
${ }^{1}$ Professora de Literatura da Rede Pública Estadual, Mestra em Estudos Literários no Programa de PósGraduação em Letras na Universidade Federal do Rio Grande do Sul, especialista em Territórios Negros (Lhiste/UFRGS) com aperfeiçoamento em Cultura e História Afro-Brasileira (FORPROF/UFRGS) e-mail: ana.flordolacio@gmail.com
} 
narrativas e serem representadas em sua história anticolonial, rejeitando séculos de silenciamento, apagamento, objetificação e estereotipação na Literatura Brasileira.

Como educadora, defendo a urgência em trabalhar a lei 10.639/03(11.645/08), que trata da obrigatoriedade do Ensino da Cultura e da História Afro-brasileira e Indígena, tema que ainda recebe muita resistência em ser contemplado pela comunidade escolar, mas que se faz cada vez mais necessário para o entendimento das relações étnico-raciais e da inclusão dos negros e índios na sociedade brasileira, essa, que foi construída sobre a égide do trabalho escravo africano e do extermínio indígena. Em janeiro deste ano, a lei completou 18 anos sem efetivar o seu propósito. A iniciativa de trabalhar com os conteúdos da cultura afro-brasileira continua sendo individual conforme constatamos na entrevista da professora Petronilha Gonçalves e Silva (2017) uma das relatoras da lei.

$\mathrm{Eu}$, professora negra, tenho consciência de que minha pessoa é uma referência de identidade para os alunos negros. Muitos se veem representados em minha pessoa e em 2016, quando introduzi no currículo da escola a escritora negra Carolina de Jesus, sentiram-se encantados com a história da vida dela: uma mulher negra que venceu barreiras e se tornou uma escritora. Eles então constataram a existência de uma História e de uma Cultura AfroBrasileira, que são formadoras do nosso país.

Nesses últimos anos, as alunas têm me questionado sobre a pequena presença de escritoras no currículo tradicional. Carolina de Jesus veio para preencher essa lacuna de representação feminina, junto com Clarice Lispector, Rachel de Queiroz e Cecília Meireles, escritoras brancas, mas ainda em menor número em relação aos escritores brancos. Contudo, a biografia de uma mulher negra que cria três filhos sozinha e passa necessidades cotidianas na luta pela sobrevivência trouxe uma identificação maior para com a maioria dos alunos que são criados em famílias chefiadas pelas mães. Em cima dessa experiência, constatei que apenas Carolina de Jesus não seria suficiente para "descolonizar" o currículo. Precisava de mais uma escritora negra e contemporânea para que o estudo da Literatura Afro-Brasileira fosse contemplado, por isso, minha escolha foi Conceição Evaristo.

O que aproxima essas duas escritoras? A própria Conceição diz que Carolina de Jesus foi quem marcou e influenciou sua escrita. Ambas cresceram na periferia, conheceram de perto a sobrevivência das mulheres negras, a pobreza, a fome. Evaristo cresceu em uma família de mulheres cozinheiras, faxineiras e babás. Carolina e Conceição foram empregadas domésticas. Conceição tomou gosto pela leitura dentro da família, que se reunia para ouvirem histórias que posteriormente ela começou a contar. A obra de Evaristo também é uma porta de acesso ao conhecimento da oralidade, um dos valores civilizatórios da sociedade africana. 
Evaristo representa na Literatura Brasileira a tradição de Carolina de Jesus: vozes divergentes e dissonantes da história única que vêm sido contada da perspectiva do colonizador, do dominador europeu. Essas vozes são o contraponto da escravidão africana, ou seja, a resistência a esse sistema. Essas vozes contam a história do Brasil pelo ponto de vista do dominado, do colonizado, do africano, do Outro. São as vozes da diáspora africana.

Rumo a um feminismo descolonial (2014), texto de María Lugones, é um desses possíveis mapas de rastreamento que nos ajudam a localizar os diversos feminismos de mulheres latinoamericanas em suas vivências e "escrevivências" que Conceição Evaristo narra em seus livros de contos: Olhos d'água e Insubmissas lágrimas de mulheres, onde a mulher negra é representada em sua complexidade, humanidade e universalidade que reúne as experiências comuns do "ser mulher negra" na América Latina.

Em Olhos d'água (2016), Evaristo trabalha com a metáfora da “água”, elemento associado à mulher por sua maleabilidade, fluidez, contorno, adaptação, purificação e sacralidade. A água também remete à maternidade, experiência que para as mulheres negras foi sequestrada durante o período da escravidão e nos dias atuais representa um risco de morte por conta da violência obstetrícia e dos riscos sobre a vida de seus filhos, que têm sido alvos do genocídio da população negra brasileira, tema de um dos contos do livro: "A gente combinamos de não morrer".

O drama das personagens é uma tensão entre a vida e a morte iminente, que ronda e espreita o povo negro. O cenário de alguns contos é de pobreza, fome, miséria e violências cotidianas nas cenas urbanas, porém, em todas as narrativas, a narradora desvenda a resistência, a resiliência e a insistência em celebrar a vida. Essa resistência é que Lugones afirma em seu texto, primeiramente como uma teórica que pensa na resistência não "como o fim ou a meta da luta política, mas sim como seu começo, sua possibilidade" (LUGONES, 2014, p. 939). Segundo Lugones (2014, p. 940), “A resistência é a tensão entre a sujeitificação e a subjetividade ativa, aquela noção mínima de agenciamento necessária para que a relação opressão $\leftarrow \rightarrow$ resistência seja uma relação ativa, sem apelação ao sentido de agenciamento máximo do sujeito moderno".

No livro de contos Insubmissas lágrimas de mulheres (2016), o sujeito, representado aqui pelas mulheres negras, não consegue conter as lágrimas diante das perdas, separações, opressões e violências, mas também, a subjetividade ativa é a própria insubmissão dessas mulheres que retrata a construção da relação opressão $\leftarrow \rightarrow$ resistência, como uma relação ativa, não subordinada.

Conceição Evaristo é apresentada na introdução desse livro como: "uma narradora que 
visita cidades em busca de histórias (e) encontra-se com as personagens que aceitam se contar, sem julgamentos prévios" (AMARO, 2016, contracapa). Os afetos e sentimentos que unem essas mulheres são a solidariedade ou "sororidade negra", que vem a ser uma aliança e empatia entre mulheres negras e que Evaristo cunhou com o termo "escrevivência".

No artigo da escritora que também é pesquisadora e Doutora em Literatura Comparada: Literatura negra: uma poética de nossa afro-brasilidade (2009), Conceição Evaristo (2009, p. 18) afirma: "Quando escrevo, quando invento, quando crio a minha ficção, não me desvencilho de um "corpo-mulher-negra em vivência e que, por ser esse 'o meu corpo, e não outro', vivi e vivo experiências que um corpo não negro, não mulher, jamais experimenta". Ela então conclui que existe uma vertente negra feminina dentro desta literatura negra:

As experiências dos homens negros se assemelham muitíssimo às minhas, em muitas situações estão par a par, porém há um instante profundo, perceptível só para nós, negras e mulheres, para o qual nossos companheiros não atinam. Do mesmo modo, penso a nossa condição de mulheres negras em relação às mulheres brancas. Sim, há uma condição que nos une, a de gênero. Há, entretanto, uma outra condição para ambas, o pertencimento racial, que coloca as mulheres brancas em um lugar de superioridade - às vezes, só simbolicamente, reconheço - frente às outras mulheres, não brancas. E desse lugar, muitas vezes, a mulher branca pode e pode se transformar em opressora, tanto quanto o homem branco. Historicamente, no Brasil, as experiências de mulheres negras se assemelham muito mais às experiências de mulheres indígenas. (EVARISTO, 2009, p. 18).

María Lugones é uma intelectual indígena, nascida no pampa argentino, é filósofa feminista, crítica social e professora de Literatura Comparada e Filosofia, Interpretação e Cultura, Filosofia e de Estudos da Mulher. Lugones cunhou o termo colonialidade de gênero em cima do conceito de "colonialidade do ser", referente ao processo de desumanização, conceito esse desenvolvido por Nelson Maldonado Torres (LUGONES apud TORRES, 2014, p. 938). Também usa o termo colonialidade seguindo a análise de Aníbal Quijano sobre o sistema de poder capitalista do mundo em termos da "colonialidade do poder" e da modernidade, onde são inseparáveis a racialização e a exploração capitalista. (LUGONES, 2014, p. 939)

Segundo Lugones (2014, p. 940), em nossas existências colonizadas, racialmente gendradas e oprimidas, somos também diferentes daquilo que o hegemônico nos torna. Esta é uma vitória infrapolítica. Aqui encontro a aproximação, de que fala Evaristo, da semelhança da experiência das mulheres indígenas com a experiência das mulheres negras. Esses dois 
grupos têm resistido em suas subjetividades à colonialidade do gênero, resistência essa que Lugones chama de Feminismo Descolonial, ou seja, a possibilidade de superar a colonialidade e compreender sua situação sem sucumbir a ela. (LUGONES, 2014, p. 941)

As mulheres indígenas, que estavam aqui nas Américas, eram seres vivos, históricos e plenamente caracterizados (LUGONES, 2014, p. 941), assim como as mulheres africanas, que foram sequestradas de seu continente, também eram seres vivos, históricos e plenamente caracterizados e é essa a revelação que Lugones intenta ao desvelar o que está eclipsado:

O sistema de poder global, capitalista, moderno colonial, que Aníbal Quijano caracteriza como tendo início no século XVI nas Américas e em vigor até hoje, encontrou-se não com um mundo a ser estabelecido, um mundo de mentes vazias e animais em evolução. Ao contrário, encontrou-se com seres culturais, política, econômica e religiosamente complexos; entes em relações complexas com o cosmo, com outros entes, com a geração, com a terra, com os seres vivos, com o inorgânico, em produção; entes cuja expressividade erótica, estética e linguística, cujos saberes, noções de espaço, expectativas, práticas, instituições e formas de governo não eram para ser simplesmente substituídos, mas sim, encontrados, entendidos e adentrados em entrecruzamentos, diálogos e negociações tensos, violentos e arriscados que nunca aconteceram. (LUGONES, 2014, p. 941).

A população negra, assim como a indígena, tentou de diversas maneiras e conseguiu manter as suas expressões culturais no período da empresa colonialista até os dias de hoje, buscando estratégias para não apagar de vez suas heranças, nem silenciar as vozes narrativas, bem como "branquear" suas identidades:

...coube aos brasileiros, descendentes de africanos, inventarem formas de resistência que marcaram profundamente a nação brasileira. Produtos culturais como a música, a dança, o jogo de capoeira, a culinária e certos modos de vivência religiosa são apontados como aspectos peculiares da nação brasileira, distinguindo certa africanidade reinventada no Brasil. Cabe ainda observar que, no campo religioso, as heranças africanas se acham presentes, tanto na fé celebrativa de uma teogonia e de uma cosmogonia negro-africanas, quanto no Candomblé e também nas formas religiosas travestidas de um sincretismo como na Umbanda, em que as divindades africanas, aparentemente encobertas pelas imagens cristãs, se atualizam como memórias não apagadas de uma fé ancestral. E mesmo no Catolicismo, percebe-se que mitos cristãos (...) como Escrava Anastácia, dentre outros, foram apropriados pelos africanos escravizados e seus descendentes, tornando-se cúmplices e protetores do povo negro. (EVARISTO, 2009, p. 19).

Retomando Lugones (2014, p. 942) e seguindo sua linha de raciocínio, o processo oprimir $\leftarrow \rightarrow$ resistir no lócus fraturado da diferença colonial é a própria identidade subjetiva 
desses "sujeitos em colaboração e conflito intersubjetivos, plenamente informados como membros das sociedades americanas, nativas ou africanas, na medida em que assumem, respondem, resistem e se acomodam aos invasores hostis que querem expropriá-los e desumanizá-los". O processo de resistência é contínuo, e o ser que habita esse lócus fraturado constituísse duplamente, “onde os lados do lócus estão em tensão, e o próprio conflito informa ativamente a subjetividade do ente colonizado em relação múltipla" (LUGONES, 2014, p. 942).

Uma aproximação que Lugones e Evaristo trazem em seus textos é a interseccionalidade. Evaristo (2009, p. 18) insiste em afirmar que além das marcações de gênero e raça, a classe social também a localiza como sujeito interlocutor com outras classes: "a sociedade que me cerca, com as perversidades do racismo e do sexismo que enfrento desde criança, somada ao pertencimento a uma determinada classe social, na qual nasci e cresci, e na qual ainda hoje vivem os meus familiares e a grande maioria negra (...), certamente influi em minha subjetividade". Lugones faz uma relação entre interseccionalidade e pureza categorial:

\begin{abstract}
...a interseccionalidade tornou-se primordial nos feminismos de mulheres de cor nos Estados Unidos... não se pode ver, localizar, ou se dirigir a mulheres de cor (mulheres latinas dos Estados Unidos, asiáticas, chicanas, afroamericanas ou indígenas norte-americanas) dentro do sistema legal dos Estados Unidos, nem em grande parte da vida institucionalizada deste país. Quando se considera as categorias dominantes, entre elas "mulher, "negro" e "pobre", vê-se que não estão articulados de maneira que incluam pessoas que são mulheres, negras e pobres. A intersecção entre "mulher" e "negro" revela a ausência das mulheres negras em vez da sua presença. (...) A relação entre pureza categorial e dicotomias hierárquicas funciona assim: cada categoria homogênea, separável e atomizada caracteriza-se em referência ao membro superior da dicotomia. Assim, "mulheres" refere-se a mulheres brancas. "Negros" refere-se a homens negros. Quando se tenta entender as mulheres na intersecção entre raça, classe e gênero, mulheres não brancas, negras, mestizas, indígenas ou asiáticas são seres impossíveis. São impossíveis porque não são nem mulheres burguesas europeias, nem machos indígenas. (LUGONES, 2014, p. 942).
\end{abstract}

Lugones (2014, p. 943) quer ver essa falha institucional não só como opressora dos seres, mas também como suas presenças são resistentes. A diferença colonial é o lócus fraturado das mulheres colonizadas e dos/as agentes fluentes em culturas nativas. Já que não podemos fugir desse lócus, é possível mudar o olhar sobre esses seres, ver mulheres negras nas narrativas onde elas são protagonistas e nas intersecções que são feitas com o opressor. Ou seja, a presença que resiste, a subjetividade ativa dos/as colonizados contra a invasão 
colonial de si próprios na comunidade desde a habitar-se a si mesmos (LUGONES, 2014, p. 943)

“A resistência à colonialidade de gênero é também vivida linguisticamente, na tensão da ferida colonial, conforme Lugones (2014, p. 945). O apagamento político, a tensão vivida do linguagismo (languaging)", que seja:

Languaging foi um termo primeiramente utilizado pelos biólogos chilenos Maturana e Varela em 1973, ao proporem uma teoria da autopoiesis. (...) Ecoando Bakthin, languagin refere-se ao "processo contínuo e simultâneo de tornarmos nós mesmos e de tornarmos nossas práticas linguísticas na medida em que interagimos e damos sentido ao mundo". (...) para Mignolo, languaging significa pensar e escrever entre linguagens, as quais estão sempre emaranhadas em relações de poder. Podemos assim dizer que languaging e worlding (termo cunhado por Spivak para se referir ao fato de que a escrita/textualidade forneceu uma estrutura retórica que justificava o domínio colonial e a expansão imperial) são processos sempre entrelaçados. (LUGONES, 2014, p. 945).

Pensar e escrever entre linguagens é usar a língua do colonizador para falar do lócus do colonizado, mas, esse processo também é mútuo: usar a língua do colonizado para falar do colonizador. Assim, o sujeito, individualmente cria a sua autopoiesis, processo contínuo e simultâneo de tornar-se alguém, de se constituir e de se autodefinir.

No artigo Literatura negra: uma voz quilombola na literatura brasileira (2010, p.1) de Conceição Evaristo, vemos esse processo contínuo e simultâneo da constituição de uma Literatura que se quer Negra. Uma Literatura Brasileira, antes de tudo:

Ao propormos uma leitura em torno da Literatura Negra julgamos necessária uma reflexão sobre a transposição e a continuidade das culturas africanas em solo brasileiro: O primeiro exercício de sobrevivência efetuado pelos africanos deportados no Brasil, assim como em toda a diáspora, foi talvez o de buscar recompor o tecido cultural africano que se desteceu pelos caminhos, recolher fragmentos, traços, vestígios, acompanhar pegadas na tentativa de reelaborar, de compor uma cultura de exílio refazendo a sua identidade de emigrante nu (GLISSANT, 1996). O homem africano no movimento de reterritorialização encontra no culto da tradição a possibilidade de viver um continuum apesar de espaço e tempo histórico diferentes. Tradição que para Muniz Sodré (1988) "Afirma-se não como forma paralisante, mas como algo capaz de configurar a permanência de um paradigma negro na continuidade histórica.". (EVARISTO, 2010, p.1).

Conceição Evaristo é uma escritora e intelectual negra brasileira que ao mesmo tempo em que escreve suas narrativas descolonizadas, pensa e reflete sobre o ato da "escrevivência" das mulheres negras e qual espaço essa Literatura feminina ocupa dentro da vertente 
Literatura Negra. O que une esses escritores negros é a experiência da diáspora, esse escrever entre linguagens, entre culturas, essa busca por uma identidade que foi fraturada, essa constituição de uma identidade nacional que foi negada e ao mesmo tempo estereotipada na formação da Literatura Brasileira e seu cânone construído sobre uma retórica colonial.

É possível a criação de uma literatura que não seja eurocêntrica, que não copie o modelo europeu, que não reproduza as relações de poder do homem branco que representa o ser negro como animalizado, sem virtudes, preguiçoso, sem alma, sem cultura, iletrado. A Literatura Negra vai ser a oposição ao status quo da Literatura Brasileira, onde o perfil de 90\% dos escritores, segundo Regina Dalcastagné (2017), é: homem, branco e da classe média. Se o contrário da "casa grande" é "quilombo", um quilombo literário é o que define a Literatura Negra:

\begin{abstract}
A palavra poética é um modo de narração do mundo. Não só de narração, mas talvez, antes de tudo, de revelação do utópico desejo de construir um outro mundo. Pela poesia, inscreve-se, então, o que o mundo poderia ser. E, ao almejar um mundo outro, a poesia revela o seu descontentamento com uma ordem previamente estabelecida. Para determinados povos, principalmente aqueles que foram colonizados, a poesia torna-se um dos lugares de criação, de manutenção e de difusão de memória, de identidade. Torna-se um lugar de transgressão ao apresentar fatos e interpretações novas a uma história que antes trazia a marca, o selo do colonizador. É também transgressora ao optar por uma estética que destoa daquela apresentada pelo colonizador. Pela poesia, o colonizado, segundo Homi Bhabba, não só encena o "direito de significar" como também questiona o direito de nomeação que é exercido pelo colonizador sobre o próprio colonizado e seu mundo. (EVARISTO apud BHABHA, 1999, p. 321).
\end{abstract}

Na criação literária, o direito à fala é assegurado. Segundo Evaristo (2010, p.3) “podese ocupar um lugar vazio apresentando uma contrafala ao discurso oficial, ao discurso do poder.” A fala na Literatura Negra não é só metafórica, ela é a base do conhecimento que foi transmitido de geração em geração, pela voz, pelo corpo, pelo gesto ancestral:

A poesia oral, presente nas culturas tradicionais africanas, foi incorporada à literatura produzida pelos poetas, contistas e romancistas africanos comprometidos com a luta de libertação do povo. A poesia foi arma, foi estratégia de luta. (...) coube aos descendentes de africanos, espalhados pelo mundo, inventar formas de resistência. Vemos, pois, a literatura buscar modos de enunciação positivos na descrição desse corpo. A identidade vai ser afirmada em cantos de louvor e orgulho étnicos, chocando-se com o olhar negativo e com a estereotipia lançados ao mundo e às coisas negras. $\mathrm{O}$ corpo negro vai ser alforriado pela palavra poética que procura imprimir e dar outras relembranças às cicatrizes das marcas dos chicotes ou às iniciais dos donos-colonos de um corpo escravo. A palavra literária como rubricaenfeite surge como assunção do corpo negro. (EVARISTO, 2010, p. 3). 
A palavra literária de Conceição Evaristo é tecida com suas rubricas-enfeites. A exaltação da beleza negra se presentifica nos corpos femininos, através da memória afetiva. No conto "Olhos d'água" (2016), a narradora ao tentar recordar a cor dos olhos de sua mãe, vai descrevendo o corpo materno como um lugar de aconchego e de alegria para os filhos: "Da unha encravada do dedo mindinho do pé esquerdo...da verruga que se perdia no meio de uma cabeleira crespa e bela... brincando de pentear boneca, ...a brincadeira preferida era aquela em que a mãe era a Senhora, a Rainha” (EVARISTO, 2016, p.16,17.)

A professora e pesquisadora de Literatura Negra Zilá Bernd indaga:

"que fator será o determinante da fissura a partir a partir da qual se pode falar em literatura negra e não apenas em temática da escravidão? E responde: 'que esse demarcador de fronteiras é o surgimento de um sujeito de enunciação no discurso poético, revelador de um processo de conscientização de ser negro entre brancos". (EVARISTO, 2010, p. 4).

O sujeito de enunciação no discurso poético, quando é um ser negro consciente das tensões raciais, é um sujeito que está abraçado ao coletivo. Quando fala de si, fala dos outros e vice-versa. Ele ressoa vozes. Segundo Evaristo (2010, p. 5), "Não podemos deixar de considerar que a experiência negra numa sociedade definida, arrumada e orientada por valores brancos, é pessoal e intransferível". É a "escrevivência”.

Esse demarcador de fronteiras que é a "escrevivência" só pode surgir numa "diferença colonial", termo escrito por Walter Mignolo e que María Lugones, a partir da complexidade do texto dele, vai construir ideias sobre a resistência à colonialidade de gênero:

\begin{abstract}
A transcendência da diferença colonial só pode ser feita a partir de uma perspectiva de subalternidade, de descolonização e, portanto, a partir de um novo terreno epistemológico onde o pensamento de fronteira é exercido. (...) As diferenças coloniais, ao redor do planeta, são a casa que a epistemologia de fronteira ocupa. (Mignolo, 2000)

Estou propondo um pensamento de fronteira feminista, onde a liminaridade da fronteira é um solo, um espaço, uma fronteira, para usar o termo de Gloria Anzaldúa, não apenas uma fenda, não apenas uma repetição infinita de hierarquias dicotômicas entre espectros do humano desalmados. (...) A leitura que eu quero efetuar vê a colonialidade de gênero e rejeição, resistência e resposta. (LUGONES, 2014, p. 947).
\end{abstract}

A sororidade das mulheres negras é a prática do feminismo descolonial. É uma rejeição da submissão e objetificação dos corpos-mulheres, é uma resistência aos estupros colonizadores aos quais as índias e as negras foram submetidas. É uma resposta à sociedade patriarcal, racimachista, que dá as costas para a realidade de um país onde a maioria dos lares 
são chefiados por mulheres.

Uma voz quilombola na literatura brasileira foi entoada pela escritora negra. Evaristo (2010, p.7) afirma que “A saga Palmarina vai ser sempre retomada. Mulheres como Dandara, Luiza Mahin, Aqualtune serão temáticas do canto poético negro". Afirmação corroborada também pela historiadora Beatriz Nascimento no texto Kilombo: "a organização quilombola, como paradigma organizativo de estratégias afirmativas dos negros que foram trazidos para as Américas" (EVARISTO, 2010, p.7).

A memória dessa ancestralidade negra brasileira é passada de mulher para mulher e conforme Lugones (2014, p.948), "pessoas que resistem à colonialidade do gênero na diferença colonial, aprendem umas sobre as outras":

(...) compreender sujeitos e enfatizar a subjetividade ativa na medida em que busca o lócus fraturado que resiste à colonialidade de gênero no ponto de partida da coalizão. Ao pensar o ponto de partida desde a coalizão, porque o lócus fraturado é comum a todos/as, é nas histórias de resistência na diferença colonial onde devemos residir, aprendendo umas sobre as outras. (...) Tudo e todos/as continuam respondendo ao poder e na maior parte do tempo respondem sem ceder - o que não quer dizer na forma de desafio aberto, mesmo que às vezes seja em desafio aberto - de maneiras que podem ou não ser benéficas para o capital, mas que são parte de sua lógica.(...) Adaptação, rejeição, adoção, desconsideração e integração nunca são só modos isolados de resistência, já que são sempre performados por um sujeito ativo, densamente construído pelo habitar a diferença colonial com um lócus fraturado. (...) Parte do que vejo é movimento tenso, pessoas se movimentando: a tensão entre a desumanização e a paralisia da colonialidade do ser, e a atividade criativa do ser-sendo. Não se resiste sozinho à colonialidade do gênero. (LUGONES, 2014, p. 948-949).

Essa reflexão nos devolve nossa humanidade roubada. Se os bancos escolares apenas reproduzem a história do negro no período escravocrata, nossas crianças nunca vão aprender sobre a resposta que demos ao poder colonial. Que nem sempre cedemos ao jugo. Que respondemos com lutas, armas, saques, incêndios. Que nos adaptamos ao cenário com nossos conhecimentos trazidos de África. Que adotamos as práticas indígenas, pelas semelhanças das cosmovisões. Que somos criativos. Que hoje construímos quilombos nas zonas urbanas.

A literatura de Conceição Evaristo coloca lado a lado mulheres negras da zona rural e da zona urbana. Mulheres letradas e analfabetas. Mulheres jovens, meninas e senhoras. Mulheres casadas, solteiras. Mulheres heterossexuais, bissexuais e lésbicas. Mulheres que são mães e outras que não querem a maternidade. Mulheres que abortam e que doam seus filhos. Mulheres artistas e mulheres burocratas. Mulheres prostitutas. Moradoras de rua. Todas as mulheres negras e suas escrevivências. 
Evaristo com suas narrativas vai recontando a história da sociedade brasileira:

Após a Abolição, a mística quilombola interiorizou-se nos descendentes livres de africanos. Não mais como uma mística de "guerra bélica declarada, mas como esforço de combate pela vida". A força vital, experimentada pelo jovem que se iniciava no Kilombo, componente do sistema filosófico bantu, está no modo de ser do brasileiro. "A aparente aceitação das dificuldades", diz Beatriz Nascimento, fundamenta-se nesta filosofia, mas é preciso fortalecer o corpo e a mente como instrumentos de luta. (...) A literatura negra toma como parte do corpus a História do povo negro vivida e interpretada do ponto de vista negro, propondo uma leitura transgressora da História oficial e escrevendo a história dos dominados. (...) Ao apropriar-me do conceito de quilombismo proposto por Abdias Nascimento e por Beatriz Nascimento, acrescento um outro aspecto talvez implícito nas considerações dos dois estudiosos. Enfatizo a diferença entre quilombo e gueto. Aprofundo aqui um pensamento de Mirian Alves, quando a poetisa afro-brasileira diz que enquanto gueto supõe impotência, quilombo traz em si a ideia de resistência, de organização. Podemos pensar o quilombo como um espaço de vivência marcado pelo enfrentamento, pela audácia de contradizer, pelo risco de contraviver o sistema. (...) Distingo ainda o quilombo de senzala, porque quilombo é um lugar de escolha, senzala como gueto, guarda um sentido de lugar vivido por imposição. Entretanto, a senzala subverte também a ordem, na medida em que é a oposição da casa-grande, constituindo-se um pólo ameaçador. (EVARISTO, 2010, p. 7-8).

Aqui ecoa o pensamento da filósofa Lélia Gonzáles, pioneira no Brasil ao pensar num Feminismo Negro Latino Americano, ou "Amefricanidade", em que a mulher assume a própria fala sobre a realidade de ser mulher africana em países colonizados da América. Lélia também criou o conceito de resistência passiva. Sim, nós, negras, resistimos aparentemente pela "passividade", mas, dessa forma, imprimimos uma identidade cultural no Brasil que está no nosso DNA até os dias de hoje:

(...) na função de mucama e/ou ama-de-leite. Nessas circunstâncias, ela mantinha um contato direto com os senhores, assim como tudo aquilo que tal contato implicava (desde a violência sexual e os castigos até a reprodução da ideologia senhorial). Mas foi justamente a partir daí que ela fez a cabeça do dominador, sobretudo ao exercer a função materna enquanto "mãe preta". (..) não se pode deixar de considerar que a "mãe preta", também desenvolveu as suas formas de resistência: a resistência passiva, cuja dinâmica deve ser encarada com mais profundidade. (...) ela foi criando uma espécie de "romance familiar" cuja importância foi vital na formação dos valores e das crenças do nosso povo. Conscientemente ou não, ela passou para o brasileiro branco as categorias das culturas negro-africanas que era representante. Foi por aí que ela africanizou o português falado no Brasil transformando-o em pretuguês e consequentemente, a cultura brasileira. (CARNEIRO, 2014, p. 41).

A escritora Conceição Evaristo, numa conferência de escritoras brasileiras em Nova 
Iorque, fez a seguinte afirmação: "Nossa história não foi escrita para ninar ao da casa-grande e sim para acordá-los dos seus sonhos injustos". (EVARISTO, site, 2018) Assim, temos a metáfora da quilombola de Lélia Gonzáles, presentificada na escrevivência de Conceição Evaristo na contemporaneidade.

As mulheres quilombolas não tinham a consciência de um feminismo como ideologia, mas, mais do que isso, o vivenciavam na prática. A literatura de Evaristo é uma potência nesse processo de reconhecimento entre mulheres negras, que buscam em suas ancestrais a força de uma luta e de uma resistência que nos ajuda a seguir.

$\mathrm{Eu}$, encontro nessas mulheres, negras e indígenas, a certeza de que sempre nossas histórias foram contadas por nós mesmas. Mesmo que ninguém quisesse escutar, mesmo que os escritos tenham sido apagados, nossa voz quilombola ecoa na Literatura Negra de Conceição Evaristo.

\section{REFERÊNCIAS}

AMARO, Vagner. Insubmissas Lágrimas de Mulheres. 2. ed. Rio de Janeiro: Malê, 2016.

BHABBA, K. Homi. O Local da Cultura. Belo Horizonte, Editora UFMG, 1999.

Brasil. Conselho Nacional de Educação. Diretrizes curriculares para a educação das relações étnico-raciais e para o ensino de História e Cultura Afrobrasileira e Africana. Brasília, 2003. $151 \mathrm{p}$.

CARNEIRO, Sueli. Lélia Gonzalez: o feminismo negro no palco da história. Brasília: Abravídeo, 2014.

DALCASTAGNÈ, R. A auto-representação de grupos marginalizados: tensões e estratégias na narrativa contemporânea. Letras de Hoje, Porto Alegre, RS, 2007, v.42, n. 4, p. 18-31, dezembro de 2007.

EVARISTO, Conceição. Insubmissas Lágrimas de Mulheres. 2. ed. Rio de Janeiro: Malê, 2016.

EVARISTO, C. Literatura Negra: uma poética de nossa afro-brasilidade. Scripta, Belo Horizonte, v.13, n.25, p.17-31, $2^{\circ}$ sem. 2009.

EVARISTO, Conceição. Literatura Negra: uma voz quilombola na literatura brasileira. In: PEREIRA, Edmilson de Almeida (Org). Um tigre na floresta de signos. Belo Horizonte, Mazza Edições; 2010.

EVARISTO, Conceição. Conceição Evaristo: nossa história não foi escrita para ninar os da Casa Grande...

Disponível em https://www.revistaforum.com.br/mariafro/2010/05/19/conceicao-evaristo- 
nossa-historia-nao-foi-escrita-para-ninar-os-da-casa-grande/ Acesso em 13/12/2018.

EVARISTO, Conceição. Olhos d'água. Rio de Janeiro: Pallas: Fundação Biblioteca Nacional, 2016.

LUGONES, M. Rumo a um Feminismo Descolonial. Estudos Feministas. Florianópolis, SC, ano 2014, n. 22 (3), p. 935-952, setembro-dezembro de 2014.

PINA, Rute, Ensino de história da África ainda não está nos planos pedagógicos, para o Brasil de fato, 09/01/2017. Disponível em: https://www.geledes.org.br/ensino-de-historia-daafrica-ainda-nao-esta-nos-planos-pedagogicos-diz-professora/ Acesso em 19/03/18.

Recebido: $25 / 08 / 2021$

Aceito: 25/01/2022 